\title{
COHERENT LIGHT SCATTERING BY NANOSTRUCTURED COLLAGEN ARRAYS IN THE CARUNCLES OF THE MALAGASY ASITIES (EURYLAIMIDAE: AVES)
}

\author{
RICHARD O. PRUM ${ }^{1}$,*, RODOLFO TORRES ${ }^{2}$, CHRISTOPHER KOVACH ${ }^{1}$, SCOTT WILLIAMSON $^{1}$ AND \\ STEVEN M. GOODMAN ${ }^{3}$ \\ ${ }^{1}$ Department of Ecology and Evolutionary Biology, and Natural History Museum, Dyche Hall, University of Kansas, \\ Lawrence, KS 66045-2454, USA, ${ }^{2}$ Department of Mathematics, University of Kansas, Lawrence, KS 66045-2142, \\ USA and ${ }^{3}$ Field Museum of Natural History, Chicago, IL 60605, USA and World Wide Fund for Nature, \\ Antanananrivo, Madagascar \\ *e-mail: prum@ukans.edu
}

Accepted 5 October; published on WWW 29 November 1999

\begin{abstract}
Summary
We investigated the anatomy, nanostructure and biophysics of the structurally coloured facial caruncles of three species in a clade of birds endemic to Madagascar (Philepittinae, Eurylaimidae: Aves). Caruncle tissues of all species had reflectance spectra with prominent, peak hues between 403 and $528 \mathrm{~nm}$. Dark blue Neodrepanis tissues had substantial reflectance in the near ultraviolet $(320-400 \mathrm{~nm})$, which is visible to birds but not to humans, providing the first evidence of ultraviolet skin colours in birds and the first indications of the possible function of ultraviolet skin colours in avian communication. These structural colours are produced by coherent scattering from arrays of parallel collagen fibres in the dermis.

accurate, but Bragg's law requires physical assumptions that are obviously violated by these structures. A twodimensional discrete Fourier analysis of the spatial variation in refractive index within the tissues documented that all the tissues are substantially nanostructured at the appropriate spatial scale to scatter visible light coherently. Predicted reflectance spectra based on the two-dimensional Fourier power spectra are relatively accurate at predicting the hue and shape of the reflectance spectra of the tissues. These results confirm that the nanostructure of the collagen arrays determines the colours that are coherently scattered by these tissues. The evolution of the anatomy and nanostructure of asity caruncles is discussed.
\end{abstract} Tissues of Philepitta castanea were organized into hexagonal, crystal-like arrays, whereas Neodrepanis tissues were quasiordered. Predictions of the peak hues of reflectance $\left(\lambda_{\max }\right)$ using Bragg's law were relatively
Key words: structural colour, coherent scattering, avian integument, collagen, Fourier analysis, Bragg's law, ultraviolet, communication, bird, asity, Philepittinae.

\section{Introduction}

The structural colours of the integument of most vertebrates are produced by intracellular arrays of crystalline purines (Bagnara and Hadley, 1973; Fox, 1976). In invertebrates, integumental structural colours are produced by laminar cuticular proteins, intracellular pigment crystals, integumentary diffraction gratings and colloidal systems (Parker, 1999). A wide diversity of birds have bright integumental colours that form a conspicuous component of their phenotype. Many of these colours are likely to be structural, since there are no blue pigments and few green pigments known in vertebrates (Fox, 1976). Despite more than a century of research on the structural colours of avian feathers (for reviews, see Auber, 1957; Dyck, 1971, 1976; Prum, 1999; Prum et al., 1999), little investigation has been made of the anatomy and physics of structural colour production in the avian skin (Lucas and Stettenheim, 1972; Prum et al., 1994). An understanding of the anatomy and physics of avian integumental structural colours is essential to investigations of the function of these colours in avian communication and to their evolutionary history within and among clades of birds.

Structural colour production mechanisms are diverse and can often be described by several different but consistent physical models (e.g. Parker, 1999). Almost all structural colour production mechanism can be understood as the result of light scattering from materials of different refractive indices within tissues. Biophysical analysis of structurally coloured tissues requires that the light-scattering behaviour of the optical heterogeneities in these tissues be described.

Traditionally, the production of structural colours in avian skin has been attributed to Rayleigh scattering by melanin granules in the dermis (Auber, 1957; Rawles, 1960; Lucas and Stettenheim, 1972; Fox, 1976). Rayleigh scattering, erroneously called Tyndall scattering (Young, 1982), is a mechanism of incoherent scattering by small particles. 
'Incoherent' scattering occurs if the phase relationships among the light waves scattered by the array can be ignored in the description of its scattering behaviour (van de Hulst, 1981; Bohren and Huffman, 1983). Incoherent scattering occurs when the scatterers (i.e. objects of a different refractive index within a tissue) are randomly distributed with respect to the size of the wavelengths being scattered (Bohren and Huffman, 1983). The Rayleigh model predicts that the efficiency of light scattering by a small particle of a given size should be inversely proportional to the fourth power of the wavelength (e.g. Fox, 1976; Young, 1982). The Rayleigh scattering hypothesis, however, has never been supported by any spectrophotometric data or microscopic observations from birds.

Prum et al. (1994) were the first to examine a structurally coloured dermal tissue from a bird using transmission electron microscopy. They documented that the structural colour in the supraorbital caruncles of the velvet asity Philepitta castanea (Eurylaimidae: Passeriformes) is produced by hexagonally ordered arrays of parallel collagen fibres in the dermis. Applying the Bragg reflection model to the average dimensions of the collagen fibre arrays, Prum et al. (1994) concluded that the collagen arrays were appropriately sized to produce the observed colours by coherent scattering. Coherent scattering models take into account the phases of different scattered waves. (Constructive interference, constructive reflection, Bragg reflection and thin-film reflection are all terms used to describe coherent light scattering.) Coherent scattering occurs when the spatial distribution of scatterers is non-random with respect to the size of the wavelength (Bohren and Huffman, 1983). Scattered waves that are out of phase will destructively interfere and cancel out, while scattered waves that are in phase will constructively reinforce one another and be coherently reflected. The phase relationships between two waves of the same wavelength scattered by different scatterers is determined by the difference between the distances travelled by each of the waves, called the path length addition. For almost all wavelengths in a medium, a given path length addition is a fraction of the wavelength. Such wavelengths will be out of phase after scattering and will destructively interfere with one another and cancel out. However, those light waves that are near to the size of the path length addition will travel a complete phase cycle over the added distance and will be in phase with one another after scattering. These wavelengths will reinforce one another to produce a wavelength-specific constructive reflection. The wavelengths that are coherently scattered by a tissue are determined by the periodicity of the spatial distribution of the scatterers (Benedek, 1971; Prum et al., 1998, 1999). If the scatterers are randomly distributed, then path length additions are also random and scattering will be incoherent. However, periodic spatial relationships among scatterers will produce a predictable distribution of path length differences among scattered waves and reinforcement of a limited set of wavelengths.

Prum et al. (1994) provided strong support for coherent scattering in $P$. castanea, but they did not conduct any spectrophotometric measurements of the colour of the tissues.
Further, their observations were limited to formalin-fixed tissues that had changed colour substantially during preservation. Thus, Prum et al. (1994) were unable to examine whether differences in colour of the caruncles were due to variation in the nanostructure of the collagen fibre arrays.

In this paper, we present detailed descriptions and comparative analyses of the colour, anatomy, nanostructure and biophysics of the brilliantly blue and green caruncles of the asities (Philepittinae, Eurylaimidae). The asities are a clade of four species of suboscine perching bird endemic to Madagascar (Amadon, 1979; Prum, 1993; Lambert and Woodcock, 1996; Prum and Razafindratsita, 1997). The genus Philepitta includes two species of medium-sized, rainforest and gallery forest bird, the velvet asity Philepitta castanea and Schlegel's asity $P$. schlegeli, which are predominantly frugivorous and nectarivorous. The genus Neodrepanis includes two small $(<8 \mathrm{~g})$ rainforest and montane forest species, the common sunbird asity $N$. coruscans and the yellow-bellied sunbird asity $N$. hypoxantha, with long decurved bills used for nectarivory and floral insectivory. Philepitta and Neodrepanis are monophyletic sister groups within the asity clade (Prum, 1993). Adult males of all asities have brilliantly coloured, sexually dimorphic facial caruncles during the breeding season (Fig. 1). These caruncles develop and atrophy annually (Prum et al., 1994; Prum and Razafindratsita, 1997) and play an important role in intersexual communication (Prum and Razafindratsita, 1997).

Here, we describe the structurally coloured caruncles of the velvet asity Philepitta castanea, the common sunbird asity Neodrepanis coruscans and the yellow-bellied sunbird asity Neodrepanis hypoxantha using light and transmission electron microscopy. The fourth species of asity, Schlegel's asity Philepitta schlegeli, is a threatened species endemic to northwest Madagascar, and specimens of its caruncle tissue were not available for analysis.

We test the hypothesis that these vivid structural colours are produced by coherent light scattering using two numerical analyses. The goal of these analyses is to use coherent scattering models to predict the hues and reflectance spectra of the tissues on the basis of their nanostructure. In the first analysis, we assume ideal lattice dimensions and apply Bragg's law (Bragg and Bragg, 1915; Prum et al., 1994) to the mean dimensions of the collagen fibre arrays to predict the peak reflected wavelengths $\left(\lambda_{\max }\right)$. However, all the tissues examined have substantial variations in size and spacing from ideal lattice dimensions that render the Bragg model inappropriate. Further, the quasiordered nanostructure of the collagen arrays of Neodrepanis (see Results) are not latticelike and clearly violate the basic assumptions of Bragg's law.

To account for deviations from a perfectly lattice-like nanostructure, we perform a two-dimensional discrete Fourier analysis of transmission electron microscope images of the tissues. The method resolves the spatial variation in refractive index in the tissue into periodic components of different spatial frequencies (Benedek, 1971; Prum et al., 1998, 1999). Spectral analysis of the Fourier transform is then used to describe the 

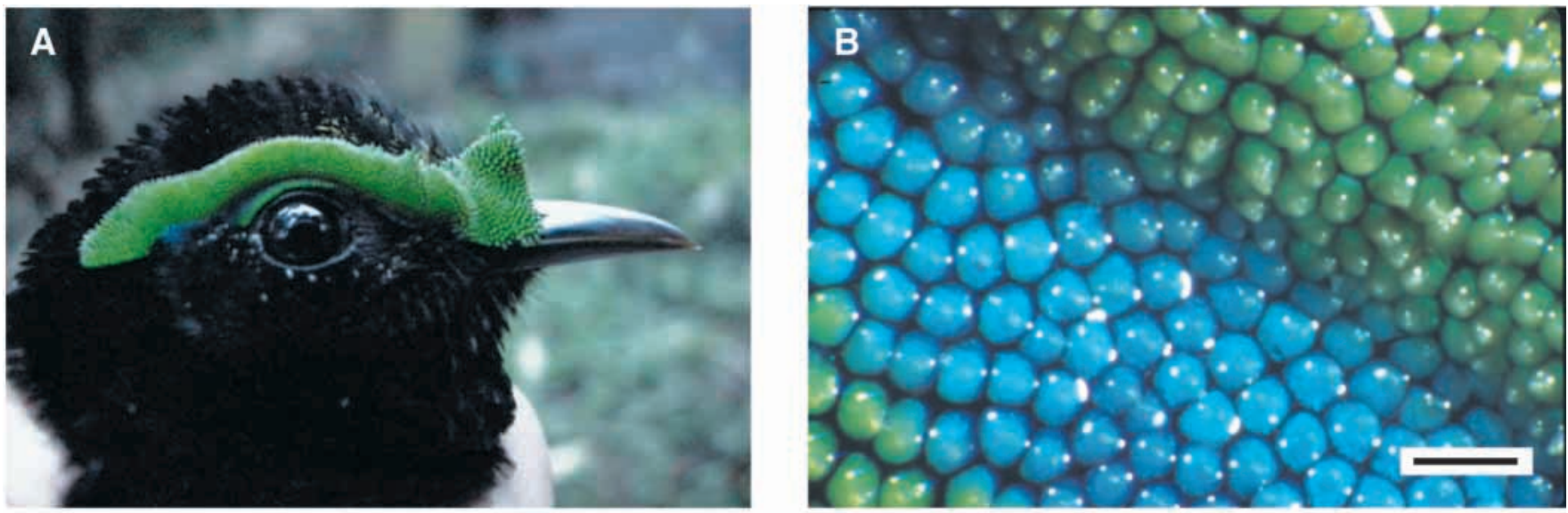

\section{D}
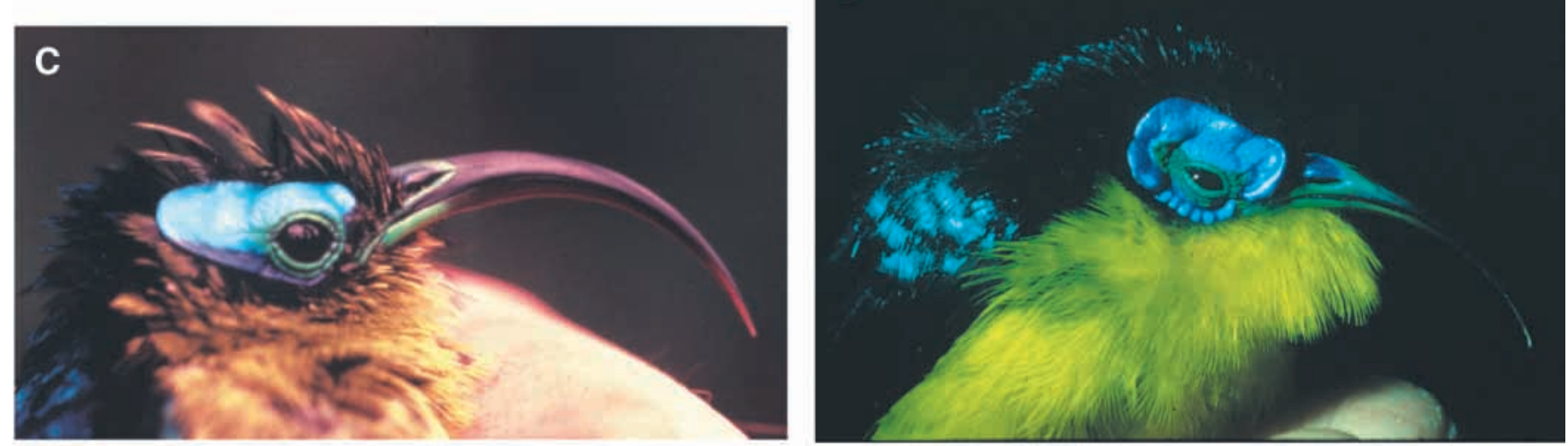

Fig. 1. Structurally coloured facial caruncles of male asities (Philepittinae: Eurylaimidae). (A) Philepitta castanea. (B) Close-up of the surface of a glutaraldehyde-preserved specimen of the supraorbital caruncle of Philepitta castanea showing the green and light blue papillae. Scale bar, approximately $500 \mu \mathrm{m}$. (C) Neodrepanis coruscans. (D) Neodrepanis hypoxantha.

periodicity of spatial variation in refractive index of the tissue and to predict the reflectance spectra of each tissue on the basis of its nanostructure (Prum et al., 1998, 1999).

Last, we discuss the evolutionary history of these colourproducing structures, the advantages and limitations of the Bragg and Fourier methods, and the function of these integumental colours.

\section{Materials and methods \\ Species sampled}

Whole left and right caruncles of adult male Philepitta castanea $(N=3)$, Neodrepanis coruscans $(N=2)$ and Neodrepanis hypoxantha $(N=2)$ were collected in the field at various localities in Madagascar and fixed in $2.5 \%$ glutaraldehyde for $1 \mathrm{~h}$ and then transferred and stored in $0.1 \mathrm{moll}^{-1}$ cacodylate buffer $\left(0.1 \mathrm{moll}^{-1}\right.$ sodium cacodylate, $0.0025 \mathrm{moll}^{-1}$ calcium chloride, $4 \%$ sucrose, $\mathrm{pH} 7.3$ ). Initially, the differently coloured portions of each caruncle were separated during preservation. However, the initial colour of the glutaraldehyde-fixed tissue samples was almost identical to the appearance of the tissues in life, so subsequent samples were not separated into different colours.

For light microscopy, specimens of caruncle tissue were embedded in paraffin, cut into $10 \mu \mathrm{m}$ sections, and stained with Masson's trichrome, which includes the collagen-specific stain Fast-Green. Caruncle tissues observed by transmission electron microscopy were taken from different areas of the caruncles, and the colour was noted. Tissues were placed in $2.5 \%$ glutaraldehyde in 0.1 mol $^{-1}$ cacodylate buffer, $\mathrm{pH} 7.3$, for $4 \mathrm{~h}$ at $4{ }^{\circ} \mathrm{C}$, and then rinsed three times for $10 \mathrm{~min}$ in buffer without glutaraldehyde at $4{ }^{\circ} \mathrm{C}$. They were then post-fixed in $1 \%$ osmium tetroxide for $1 \mathrm{~h}$, rinsed three times for $10 \mathrm{~min}$ in distilled water at room temperature, stained with $0.5 \%$ aqueous uranyl acetate for $2 \mathrm{~h}$ and rinsed twice for $10 \mathrm{~min}$ with distilled water. Tissue pieces were then dehydrated through an ethanol series and embedded in Embed 812. They were sectioned, approximately $80 \mathrm{~nm}$ thick, with a diamond knife. Specimens were viewed and photographed with a JEOL EXII transmission electron microscope.

Thirty-five measurements of the diameter of collagen fibres and the minimum distance between adjacent fibres (referred to below as the interfibre spacing) were made using digital calipers directly from the micrograph negatives.

\section{Spectrometry}

The reflectance spectra were measured using an Ocean Optics S2000, a fibre-optic diode array spectrometer, with an 
Ocean Optics PX-2 pulsed xenon light source. This spectrometer produces 2048 reflectance data points between 160 and $865 \mathrm{~nm}$ (1520 pixels from 300 to $800 \mathrm{~nm}$ ) with an average error of $0.14 \mathrm{~nm}$. Measurements were made with perpendicularly incident light from approximately 2 to $3 \mathrm{~mm}$ from the specimen from an illuminated field of approximately 2-3 $\mathrm{mm}^{2}$ with a $100 \mathrm{~ms}$ summation time. A compressed tablet of barium sulphate $\left(\mathrm{BaSO}_{4}\right)$ was used as a white reference standard, and the ambient light of a darkened room was used as a dark reference. Percentage reflectance $(\% R)$ values for each wavelength were calculated automatically from measurements of light-scattering intensity using:

$$
\% R=\frac{S-D}{W-D} \times 100,
$$

where $S$ is the reflectance of the specimen, $D$ is the reflectance of a dark standard and $W$ is the reflectance of a white standard. Reflectance spectra for each distinctly coloured area of the caruncles of each species were calculated from averages of percentage reflectance values from 10 measurements from each specimen. Average reflectance spectra were further characterized in terms of hue (peak reflectance, $\lambda_{\max }$ ) and saturation, or chroma, which is measured here as the inverse of the breadth of the peak at half its height. To control for the effects of any potential epidermal pigments on the reflectance spectra of the green papillae from the caruncles of $P$. castanea, additional reflectance spectra were measured from a $3 \mathrm{~mm}^{2}$ area from which the keratin cones and epidermis were dissected away from the papillae.

\section{Bragg analyses}

The relationship between the spacing of the scatterers in a perfect lattice and the peak wavelength of reflection is given by Bragg's law (Bragg and Bragg, 1915), which has been adapted for application to biological arrays (Durrer, 1962; Durrer and Villiger, 1966, 1970; Prum et al., 1994). The peak of wavelength of reflectance $\left(\lambda_{\max }\right)$ is given by:

$$
\lambda_{\max }=n 2 d \sin \theta,
$$

where $d$ is the distance between neighbouring scatterers, $\theta$ is the angle of incident light, and $n$ is the average refractive index of the medium. In previous biological applications of Bragg's law (Durrer, 1962; Durrer and Villiger, 1966, 1970; Prum et al., 1994), $n$ was taken to be the refractive index of the medium between the scattering objects but, since the scattered waves that contribute to the observed colour are propagated through both substances in the tissue, the correct value for $n$ is the average refractive index of the entire tissue (Benedek, 1971). We applied the Bragg equation to the sum of the mean collagen fibre diameters and interfibre spacings $(d)$, assuming directly incident light $\left(\sin 90^{\circ}=1\right)$ and using an average refractive index of $1.45(n)$ to produce a predicted $\lambda_{\max }$ for each colour of caruncle tissue from each species. This simple application of the Bragg equation assumes perfect lattice spacing, which is impossible for even the most highly ordered biological materials.

\section{Two-dimensional Fourier analysis}

Coherent scattering of visible wavelengths is the consequence of nanoscale spatial periodicity in the variation in refractive index of the tissue (Benedek, 1971; Prum et al., 1998, 1999). Benedek (1971) and Vaezy, Clark and colleagues (Gisselberg et al., 1991; Vaezy and Clark, 1991, 1993, 1995; Vaezy et al., 1995a,b) developed an application of twodimensional Fourier analysis to analyze the optical transparency of the vertebrate cornea. Prum et al. (1998, 1999) developed the Fourier method further for the analysis of structural colour production by biological tissues.

Discrete Fourier analysis transforms a sample of data points into an equivalent sum of component sine waves of different frequencies and amplitudes (Briggs and Henson, 1995). The amplitude of each Fourier component wave expresses the relative contribution of that frequency of variation to the periodicity of the original data. The variation in the squared amplitudes over all Fourier components is called the Fourier power spectrum. The relative values of the different Fourier components in the power spectrum express the comparative contribution of those frequencies of variation to the total power of the original function. This application of Fourier analysis is derived independently from electromagnetic optical theory (Benedek, 1971) and is unrelated to the traditional physical field of 'Fourier optics' in which the Fourier transform is used to describe the process of diffraction by a grating or the resolution of an image by a lens.

The first step in the discrete Fourier analysis was to digitize the transmission electron micrographs of caruncle tissue of various colours of the three species at 300 dpi using a HewlettPackard Scanjet 3c (Fig. 2A). The digitized transmission electron microscope images were analyzed using MATLAB (Version 5.0) on a Silicon Graphics Onyx workstation. The scale of each digitized image (nm per pixel) was calculated by measuring the number of pixels in the scale bar in the micrograph. Images were then processed to enhance the distinction between the collagen fibres and the mucopolysaccharide matrix (i.e. the spatial function of refractive index) and to reduce variation within each material (i.e. noise). The intensity of pixels in the image was rescaled using the original variance in intensity. Pixels more than one standard deviation away from the mean intensity value were assigned to 0 (black) or 1 (white), and the remaining variation was rescaled as a linear function between 0 and 1 . To eliminate variation among different areas of the image, this variance rescaling was performed repeatedly across the entire image on $30 \times 30$ pixel submatrices with five overlapping pixels. Pixel intensity was then median-filtered; each pixel received the median of the surrounding $4 \times 4$ pixel matrix. The largest available square portion of the array was then selected for analysis; this varied from 784 to 860 pixels $^{2}$.

The average refractive index of the tissue in each image was estimated by generating a two-partition histogram of image density (i.e. the distribution of darker and lighter pixels) from the processed images. The frequency distributions of the darker and lighter pixels were used to estimate the relative frequency 

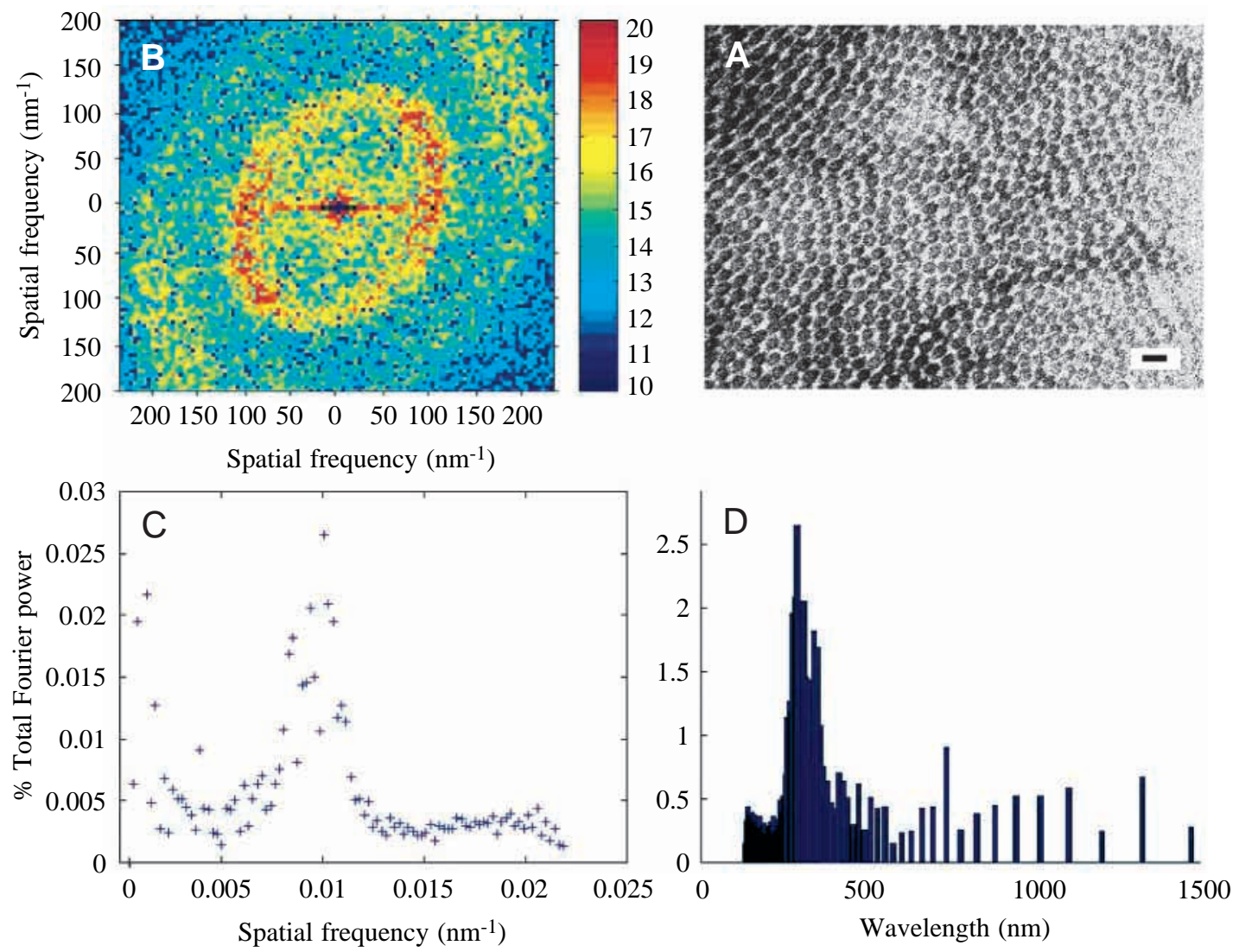

Fig. 2. The two-dimensional Fourier transform method for analysis of nanostructure and colour production by biological arrays, proceeding counter-clockwise from the upper right. (A) Transmission electron micrograph of a collagen array from dark blue caruncle tissue of Neodrepanis hypoxantha. Scale bar, $200 \mathrm{~nm}$. (B) Two-dimensional Fourier power spectrum of the Neodrepanis hypoxantha tissue. The magnitude of each value in the power spectrum is given by the colour (scale on right). Magnitudes are illustrated here as natural logarithms of the original values, but the original data are used in all calculations. (C) Normalized radial average of one quadrant of the two-dimensional Fourier power spectrum expressed in terms of spatial frequency $\left(\mathrm{nm}^{-1}\right)$ and percentage total Fourier power. (D) Fourier-predicted reflectance spectrum of the tissue expressed in terms of wavelength (nm) and percentage total Fourier power. See Materials and methods for details.

of collagen and mucopolysaccharide in the image and to calculate a weighted average refractive index for the tissue. Here, the refractive index is used in calculating the differences in optical distance travelled by waves scattered by different objects in the tissue. The weighted average is the appropriate quantity because it estimates the refractive index experienced by a wave propagated through the tissue without scattering. The refractive index of collagen has been estimated as 1.55 , and the refractive index of the mucopolysaccharide in the collagen matrix of the human cornea has been estimated as 1.35 (Maurice, 1984).

The numerical computation of the Fourier transform was performed using the well-established two-dimensional Fast Fourier Transform (FFT2) algorithm (Briggs and Henson, 1995) in MATLAB (MATLAB Research Guide, 1992; Thompson and Shure, 1995). We then calculated the twodimensional Fourier power spectrum, or the distribution of the squares of the Fourier coefficients (Fig. 2B). The twodimensional Fourier power spectrum resolves the spatial variation in refractive index in the tissue into its periodic components in any direction from a given point. The four quadrants of the power spectra were shifted to place the frequency origin in the centre of the image. The twodimensional Fourier power spectra were expressed in spatial frequency $\left(\mathrm{nm}^{-1}\right)$ by dividing the initial spatial frequency values by the length of the matrix (pixels in the matrix multiplied by nm per pixel). Each value in the two-dimensional power spectrum reports the magnitude of the periodicity in the original data at a specific spatial frequency in a given direction from all points in the original image. The spatial frequency and direction of any given component in the power spectrum are given by the length and direction, respectively, of a vector from the origin to that point, and the magnitude is depicted by the colour (Fig. 2B).

We produced predicted reflectance spectra based on the twodimensional Fourier power spectra, the scale and the average refractive index of the images. These reflectance spectra are predictions about the relative magnitude and distribution of coherently scattered wavelengths on the basis of the experimentally observed spatial periodicity in the material. First, an estimate of the percentage total Fourier power distributed among component waves of different sizes was 


\section{R. O. PRUM AND OTHERS}

produced by averaging a series of 0.5 pixel radial intervals of spatial frequency (diameters) for a single quadrant of the power spectrum. The values of the radial average of the power spectrum were then rescaled so that the total volume (and total energy) under the rotated radial average power function was equal to 1. Next, the relative percentage total power of Fourier components of different sizes (over all directions) was estimated by calculating the volumes of radial segments, or shells, of the normalized, rotated, radial average of the power spectrum (Fig. 2C). The inverses of the spatial frequency values were then multiplied by twice the average refractive index of the medium and expressed in terms of wavelength (nm) (Fig. 2D). Here, as in Bragg's law, the wavelength scattered is equal to twice the spatial periodicity times the average refractive index. In this calculation, however, the differential magnitude of the Fourier components yields a prediction about the relative magnitude of scattered light of different wavelengths. The result is a theoretical prediction of the relative magnitude of coherent scattering, or constructive interference, by the tissue that is based entirely on the spatial variation in refractive index of the tissue.

\section{Results \\ Colour and anatomy}

The colour of the caruncles of male asities varies among species and among areas of the caruncle within each species. In $P$. castanea, the supraorbital caruncle is vivid green with a brilliant royal blue horizontal stripe in the centre of the caruncle (Fig. 1A,B). The caruncle is extensible. At rest, the blue stripe is largely hidden within a wrinkle in the caruncle surface, but when the caruncle is fully extended during several intersexual displays (Prum and Razafindratsita, 1997), the horizontal blue stripe is strikingly visible above the eye. The surface of the caruncles of $P$. castanea is covered with coneshaped papillae that contain the colour-producing collagen (Fig. 1B). Each papilla is $350-500 \mu \mathrm{m}$ tall and consists of a cone-shaped keratinized epidermal sheath covering a spherical capsule of irregularly oriented, cylindrical collagen macrofibrils that are approximately $100 \mu \mathrm{m}$ long and $10-20 \mu \mathrm{m}$ wide (Fig. 3A). The base of the papilla contains a dense layer of melanocytes that rest on the unstructured collagen, numerous fine muscle fibres and blood vessels of the dermis below (Fig. 3B,C). The collagen within a single papilla produces either a distinctly blue or green hue. The blue and green portions of the caruncle are covered exclusively by papillae of the corresponding hue (Fig. 1B). The distal tip of the keratin sheaths of most green papillae are greenish to yellowish in colour (Fig. 1B), implying the presence of an unknown pigment within the keratin of the papillary sheath. However, the collagen within the green papillae appears green through the unpigmented sides of the papillae and if the epidermal sheath is removed. The blue papillae have slightly opaque or whitish sheaths that apparently lack any pigmentation.

In contrast, the caruncles of both species of Neodrepanis encircle the eyes, extend onto the ramphotheca at the base of the bill and have smooth surfaces that lack papillae. In $N$. coruscans and $N$. hypoxantha, the colour and shape of the caruncle vary individually but are also different between the two species (Fig. 1C,D). In $N$. coruscans, the caruncle is generally light sky blue above and behind the eye, dark violet blue below the eye and greenish-yellow in a thin ring immediately around the eye and leading rostrad to the base of the beak in a 'spectacle' pattern (Fig. 1C). In N. hypoxantha, the caruncle is generally light sky blue, with darker royal blue patches towards the caudal margin in some individuals and a larger yellow-green eye ring or 'spectacles' (Fig. 1D). In both species of Neodrepanis, the caruncle consists of a thin epidermis $10-20 \mu \mathrm{m}$ thick that covers a layer of collagen between 250 and $500 \mu \mathrm{m}$ thick that is underlain by a layer of melanocytes (Fig. 3D-G). Unlike those in $P$. castanea (Fig. 3B,C), the collagen macrofibrils in Neodrepanis are more convoluted, 'wavy' and interconnected (Fig. 3E,G). The collagenocytes are small and generally dispersed in Neodrepanis (Fig. 3E,G), whereas in P. castanea the collagenocytes are larger and appear to form a network of interconnected cells that separate the collagen macrofibrils (Fig. 3B,C). No differences were apparent in the anatomy of the differently coloured portions of the caruncles in either species of Neodrepanis. Unlike those of P. castanea, the caruncles of Neodrepanis are not extensible and lack the prominent dermal muscle fibres that provide caruncle movement in $P$. castanea.

No specimens of the caruncle tissue of Philepitta schlegeli were available for analysis. Examination of study skins and published photographs record that the caruncle has rounded pre-ocular and postocular lobes (Hawkins, 1994). The caruncle is mostly vivid fluorescent green with a vertical stripe of brilliant royal blue in the centre running through the eye (Hawkins, 1994). Under a dissecting microscope, the surface of the caruncle of traditional study skins is not covered in coneshaped papillae as in Philepitta castanea. Rather, the caruncle surface is smooth as in Neodrepanis, but with unique, broadly rounded undulations or 'bubbles.' It is not known whether the caruncles of $P$. schlegeli are extensible as in $P$. castanea.

\section{Spectrometry}

The reflectance spectra of all asity caruncles are strongly unimodal with prominent peak hues and strong saturation (limited breadth at half the peak) (Fig. 4; Table 1). None of the reflectance spectra shows any similarity to the inverse fourth power relationship predicted by the Rayleigh scattering model. The peak hues of the reflectance spectra of each coloured area of the caruncles of each species vary as predicted by the initial visual classification of the colours of the tissues. The peak hues of the dark blue tissues of both species of Neodrepanis (Fig. 4C,E) are at the limit between the human visible spectrum $(400-700 \mathrm{~nm})$ and the near ultraviolet $(320-400 \mathrm{~nm})$. Nearly half the colour produced by these tissues is in the nearultraviolet range that is visible to birds (Bennett and Cuthill, 1994). These data provide the first evidence of near-ultraviolet 

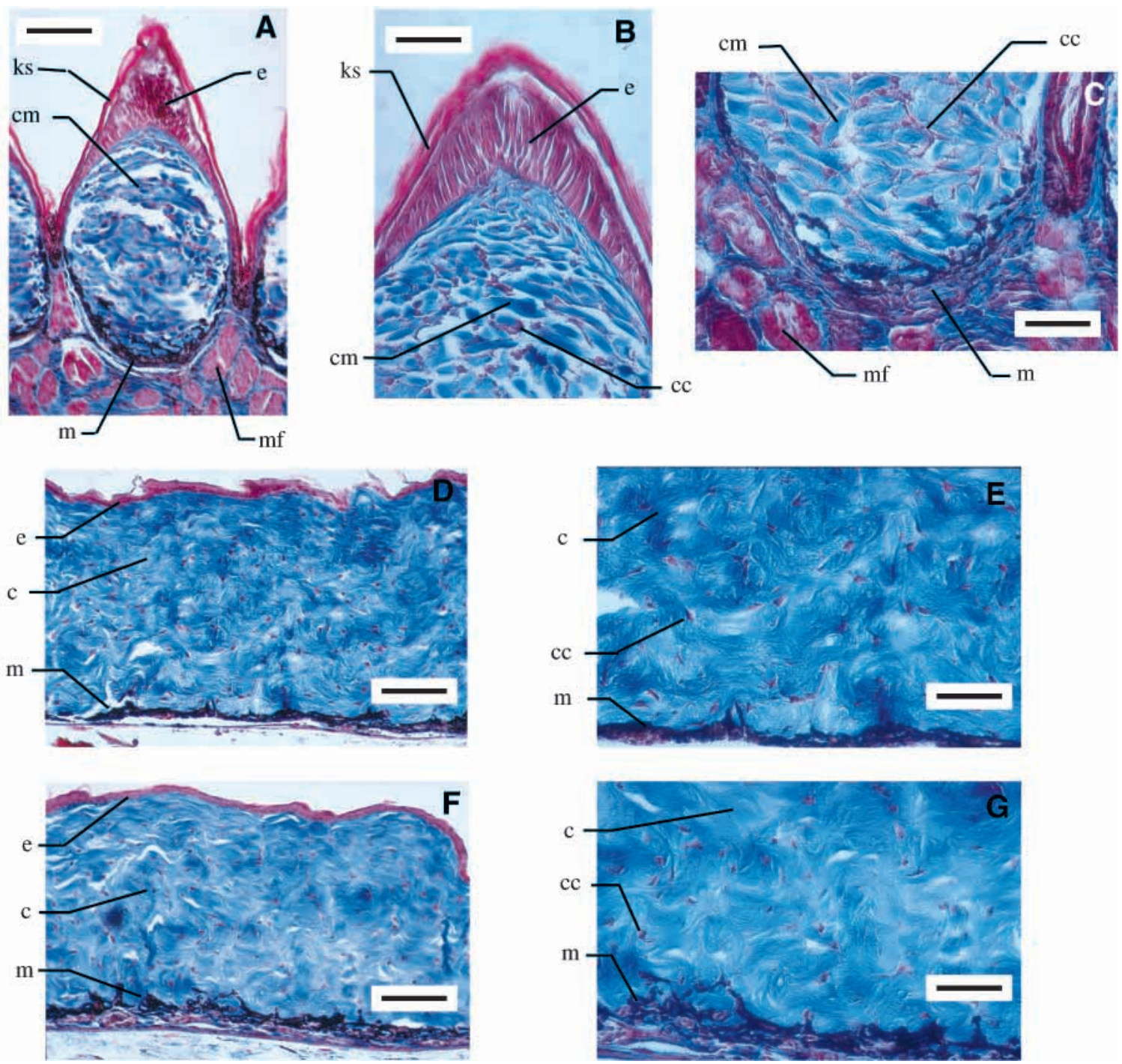

Fig. 3. Light micrographs of cross sections of colour-producing caruncles of asities. (A) Papilla of Philepitta castanea with a capsule of colourproducing collagen macrofibres in the centre. (B) Distal tip of the papilla of Philepitta castanea. (C) Base of a papilla and the underlying dermal tissue in Philepitta castanea. (D) Colour-producing caruncle of Neodrepanis coruscans. (E) Base of the colour-producing caruncle of Neodrepanis coruscans. (F) Colour-producing caruncle of Neodrepanis hypoxantha. (G) Base of the colour-producing caruncle of Neodrepanis hypoxantha. Specimens are stained with Masson's Trichrome: collagen is stained blue, and keratin, epidermis, collagenocytes and muscle fibres are stained red. Scale bars A,D,F, $100 \mu \mathrm{m}$; B,C,E,G, $50 \mu \mathrm{m}$. e, epidermis; c, collagen; cc, collagenocytes; cm, collagen macrofibres; ks, keratin sheath; m, melanocytes; mf, muscle fibres.

colours in the skin of birds, and the first indication that nearultraviolet skin colour may function in avian communication. The greenish and yellowish portions of the caruncles of Neodrepanis were too small in area $\left(<1 \mathrm{~mm}^{2}\right)$ to be measured accurately. The reflectance spectra of the green portions of the caruncles of $P$. castanea had identical peaks whether or not the potentially pigmented keratin cones and epidermis were intact or dissected away.

The magnitude of the reflectance peaks, or brilliance, of the colours varied extensively with colour and species (Fig. 4; Table 1). Much of this variation appears to be related to preservation artefacts in individual specimens and not to the vividness of the colours in life. For example, the blue and green portions of the caruncles of $P$. castanea are equally vivid in life, but the blue portions are almost twice as brilliant in the preserved specimens (Fig. 4A,B).

The tissue specimens were collected in Madagascar between 1994 and 1996. Although the original fixation preserved the colours extremely well, the hue and brilliance of some specimens has apparently changed during the subsequent 4-5 years of refrigeration in cacodylate buffer. Original reflectance spectra are not available, but a comparison of contemporary specimens of $P$. castanea with colour photographs of the same specimens from 1994 demonstrates that some originally royal blue areas have become turquoise (Fig. 1B). Today, the reflectance spectra peak of this turquoise area is at approximately $520 \mathrm{~nm}$, or closely approaching the recorded peak of $528 \mathrm{~nm}$ for the green portions. 

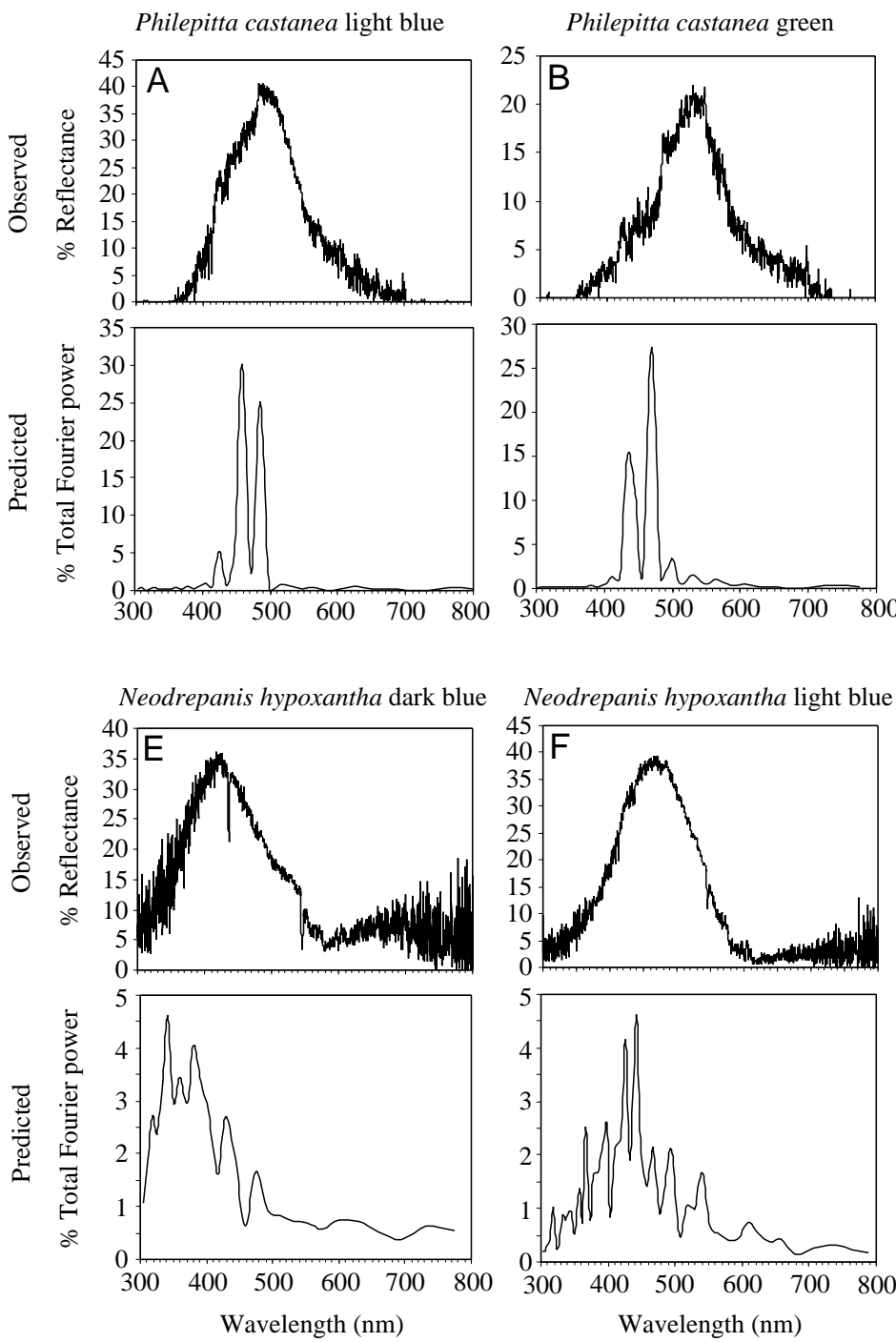

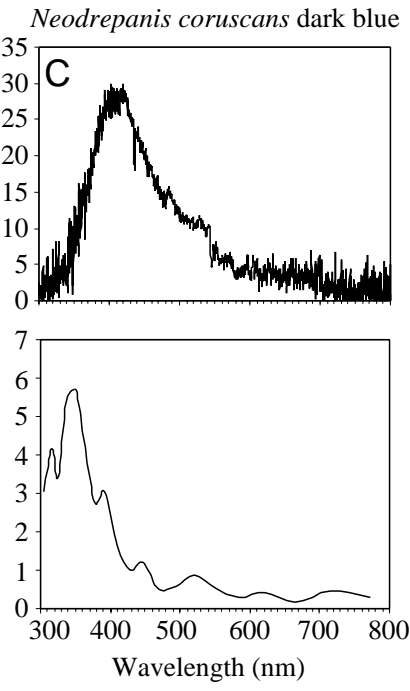

Neodrepanis coruscans light blue
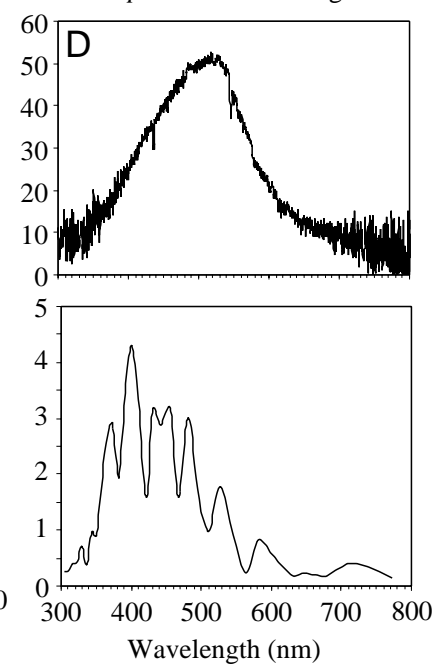

Fig. 4. Observed (above) and predicted (below) reflectance spectra of glutaraldehyde-preserved caruncle tissue of asities. Philepitta castanea: (A) light blue, (B) green. Neodrepanis coruscans: (C) dark blue, (D) light blue. Neodrepanis hypoxantha: (E) dark blue, (F) light blue. Observed reflectance spectra were measured using a fibre-optic spectrophotometer. Predicted reflectance spectra were calculated from the twodimensional Fourier power spectrum of the transmission electron microscope images of the tissues and their average refractive indices.

\section{Nanostructure}

Transmission electron micrographs of the collagen macrofibrils in the dermal papillae of $P$. castanea reveal a highly ordered array of hexagonally packed collagen fibres (Fig. 5A,B). In contrast, the collagen fibres in the caruncles of $N$. coruscans and $N$. hypoxantha are quasiordered (Fig. 5C-F): the collagen fibre diameters and interfibre spacing are unimodal in distribution, but the angles between fibres are not rigidly crystalline or lattice-like, as they are in $P$. castanea.

The collagen fibres in the differently coloured areas of the caruncles of each species are significantly different in diameter (one-way ANOVA; $P<0.001$; Table 1). Interfibre spacing was significantly different between colours of $N$. coruscans and $N$. hypoxantha but not in $P$. castanea. In most instances, both fibre diameter and interfibre spacing are positively associated with the peak hue of the tissue (Table 1). However, the dark blue $N$. hypoxantha tissue is exceptional in having among the widest collagen fibres with the smallest interfibre spacing and the smallest peak hue (see below; Table 1).

Some sections from the green and light blue portions of caruncles from both $N$. coruscans and $N$. hypoxantha show a strong, but highly local, tendency towards hexagonal order (see Fig. 8). In these sections, the interfibre spacing and angles briefly approach the strikingly hexagonal order that is uniformly present in $P$. castanea.

\section{Bragg analysis}

The predictions of $\lambda_{\max }$ produced using Bragg's law ranged from 18 to $132 \mathrm{~nm}$ (mean $69 \mathrm{~nm}$ ) smaller than the observed $\lambda_{\max }$ (Table 1). The Bragg model accurately predicted the relative wavelengths of $\lambda_{\max }$ for differently coloured tissues of each species and was a fairly accurate predictor of the relative $\lambda_{\max }$ of all tissues (Pearson correlation coefficient between observed and predicted $\lambda_{\max }=0.771$ ). The Bragg predictions of $\lambda_{\max }$ were most accurate for the two colours of $P$. castanea, in which the nanostructure is more clearly lattice-like and the assumptions of the model are better met. The Bragg model does not predict the shape of the reflectance spectrum of the tissue.

\section{Two-dimensional Fourier analysis}

The two-dimensional Fourier power spectra of $P$. castanea caruncle tissue show six discrete peaks arranged hexagonally 


\section{Colour-producing collagen arrays in birds 3515}

around the origin at intermediate spatial frequency values (Fig. 6A,B). They also show additional, lower-magnitude secondary harmonic peaks located at angles between the fundamental peaks and at twice the spatial frequency of the fundamental peaks, and even tertiary harmonics at longer spatial frequencies. In contrast, the two-dimensional Fourier power spectra of all colours of both species of Neodrepanis have a single high-magnitude, intermediate-spatial-frequency ring around the origin, with an additional lower-magnitude harmonic ring at twice the fundamental spatial frequency (Fig. 6D-G). Because variations in refractive index of a particular spatial frequency are inversely related to the wavelength they will coherently scatter, the tissues that produce smaller-wavelength colours have spectral peaks or rings of larger spatial frequency (Fig. 6).

The ring-like power spectra of Neodrepanis tissue indicate that the periodicity of spatial variation in refractive index is equivalent in all directions in this plane within the tissue. The slightly oval power spectra of light blue Neodrepanis hypoxantha tissue (Fig. 6G) is due to a slightly biased cross section of the fibres. In contrast, the hexagonally patterned power spectra of $P$. castanea indicate that there is substantial variation among directions in the spatial periodicity of the tissue. The highest-magnitude Fourier components in the $P$. castanea power spectrum are discrete peaks in the directions of nearest neighbouring fibres in the hexagonal array (Figs 5A,B, 6A,B). This result was tested explicitly by performing identical two-dimensional Fourier analyses of the same tissue images rotated by different angles. The positions of the six peaks in the resulting power spectra were rotated by the same angles as the original images. The harmonic spatial frequency peaks appeared at twice the fundamental spatial frequency, but in directions that bisected the angles of the fundamental peaks. These peaks represent the component spatial frequency in the direction that runs between next-tonearest neighbouring fibres of the array. As predicted by Fourier theory (e.g. Senechal, 1996), the differences in nanostructure of the collagen arrays are accurately depicted in the two-dimensional Fourier power spectra of transmission electron microscope images of the tissues.

In tissues of all colours from each species, the normalized radial averages of the Fourier power spectra show peaks at intermediate spatial frequency values that demonstrate that these tissues are significantly nanostructured (Fig. 7). Furthermore, the inverses of the peak spatial frequencies are closely correlated with the average distance between fibre centres (i.e. the sum of diameter and interfibre distance; Table 1; Pearson correlation coefficient=0.944). Thus, the predominant spatial frequency in the two-dimensional power spectra of the tissue was determined by the average distance between fibre centres. The radial average power spectra also show that the $P$. castanea tissues are much more periodic than the Neodrepanis tissues. Expressed in terms of the percentage of the total power in the Fourier power spectrum, the values of the peak spatial frequencies in $P$. castanea tissue (27-30\%) are an order of magnitude higher than in any Neodrepanis tissue (4-6\%) (Fig. 7).

The Fourier-predicted reflectance spectra all show predominant peaks in the avian visible spectrum (Fig. 4). The wavelengths of the peaks of the Fourier-predicted reflectance spectra were $24-117 \mathrm{~nm}$ (mean $77 \mathrm{~nm}$ ) smaller than the observed values of $\lambda_{\max }$ (Fig. 4; Table 1). Although these errors are substantial, the Fourier-predicted spectra give an accurate description of the relative positions of the peaks of the differently coloured tissues. Within each species, the tissues with smaller-wavelength hues had Fourier-predicted spectra with the smaller-wavelength peaks. The Fourier-predicted reflectance spectra also predicted the relative hues of all tissues with the exception of light blue Neodrepanis hypoxantha tissue

Table 1. Colour, nanostructure and physical analyses of asity collagen arrays

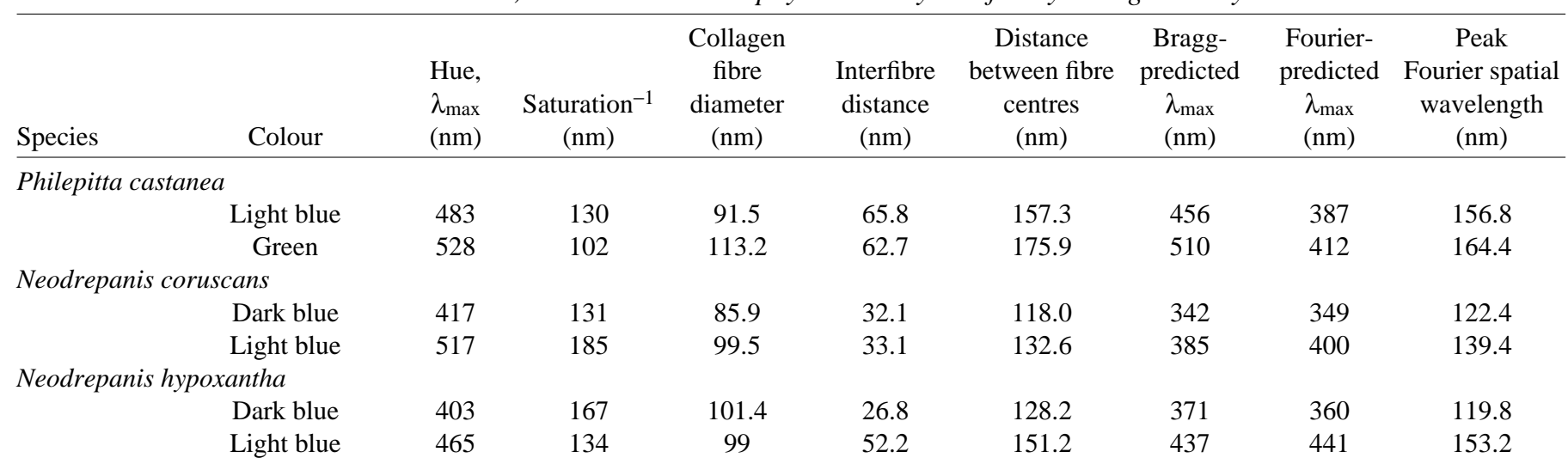

See Materials and methods for details.

Saturation, or chroma, is inversely related to the breadth of the reflectance peak and is reported here as the width of the reflectance peak at half its height; smaller values indicate higher saturation.

Peak Fourier spatial wavelength $(\mathrm{nm})$ is the inverse of the peak spatial frequency $\left(\mathrm{nm}^{-1}\right)$ from the normalized radial averages of the twodimensional Fourier power spectra. These values estimate the average distance between fibre centres.

For measurements of fibre diameter and interfibre distance, $N=35$; for hue and saturation, $N=10$. 
(Pearson correlation coefficient between observed and predicted $\lambda_{\max }=0.657$ ). The observed $\lambda_{\max }$ of the light blue Neodrepanis hypoxantha tissue was intermediate within the six tissues sampled, but its Fourier-predicted $\lambda_{\max }$ was the largest.
The Fourier-predicted reflectance spectra are generally similar to the observed spectra in their central tendency and breadth, but the Fourier-predicted spectra have much more jagged profiles (Fig. 4). These deviations are a result of
Philepitta castanea light blue

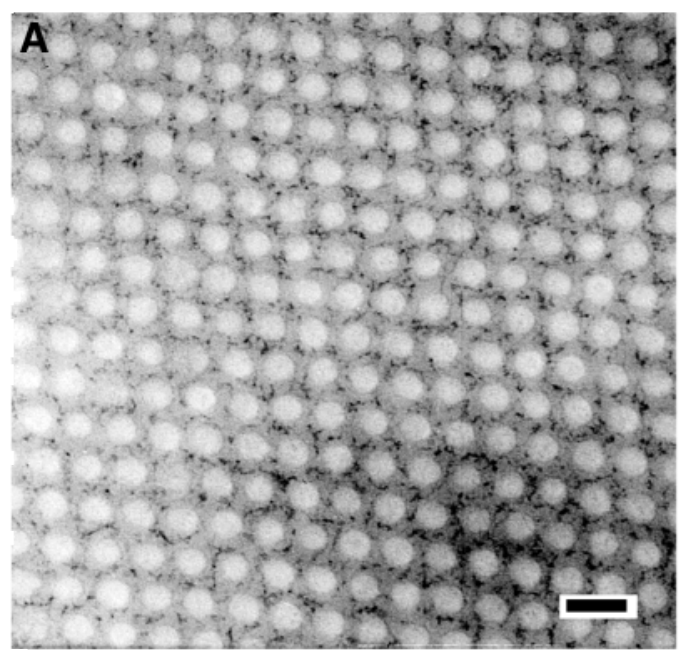

Neodrepanis coruscans dark blue

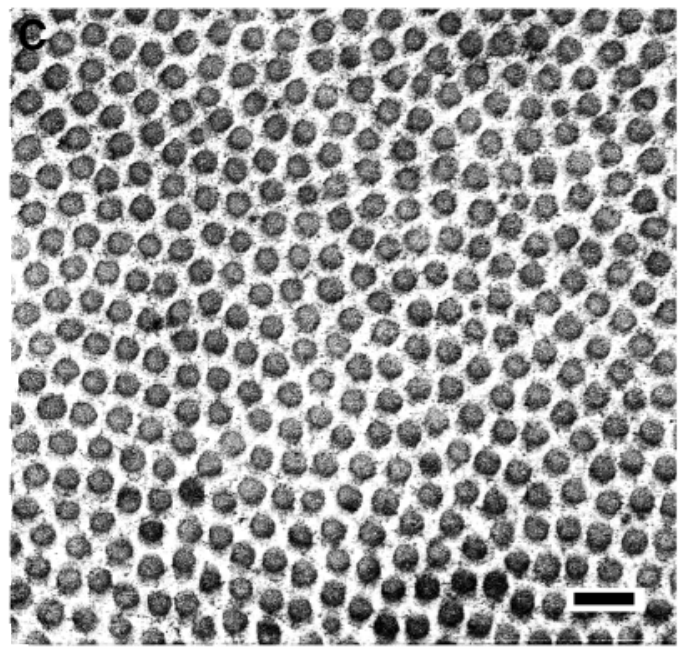

Neodrepanis hypoxantha dark blue

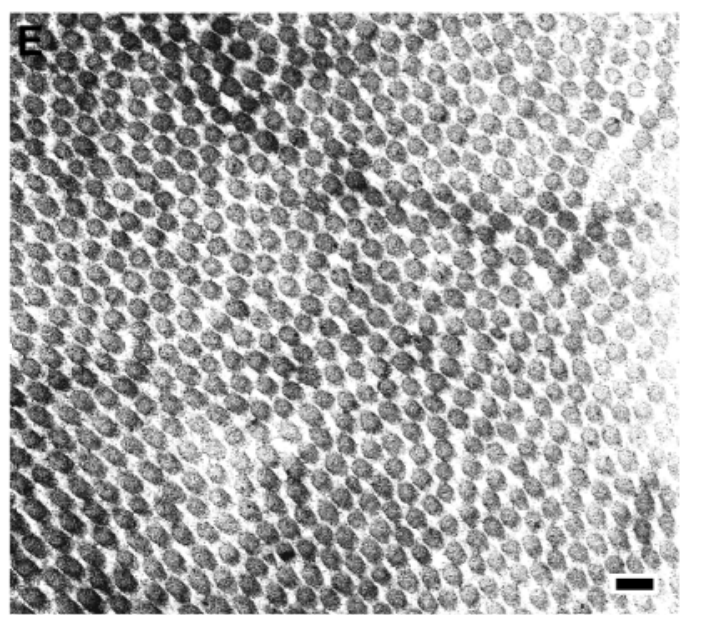

Philepitta castanea green

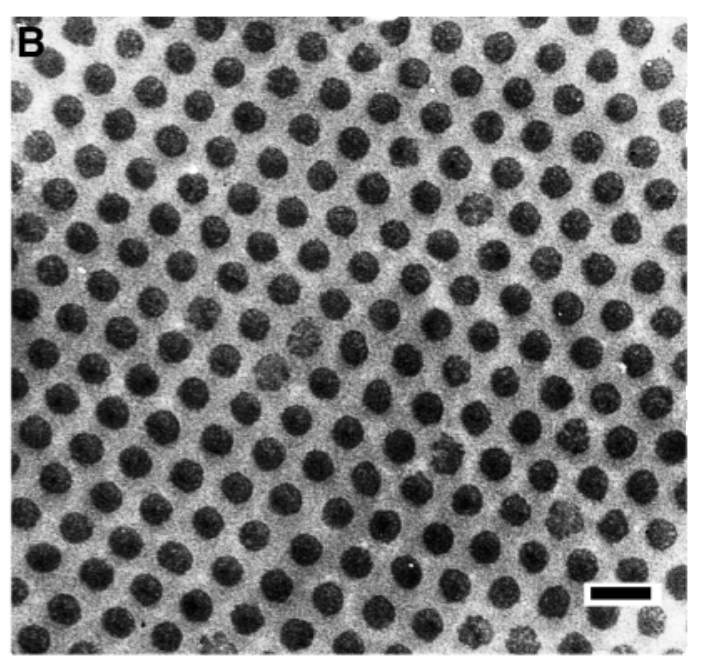

Neodrepanis coruscans light blue

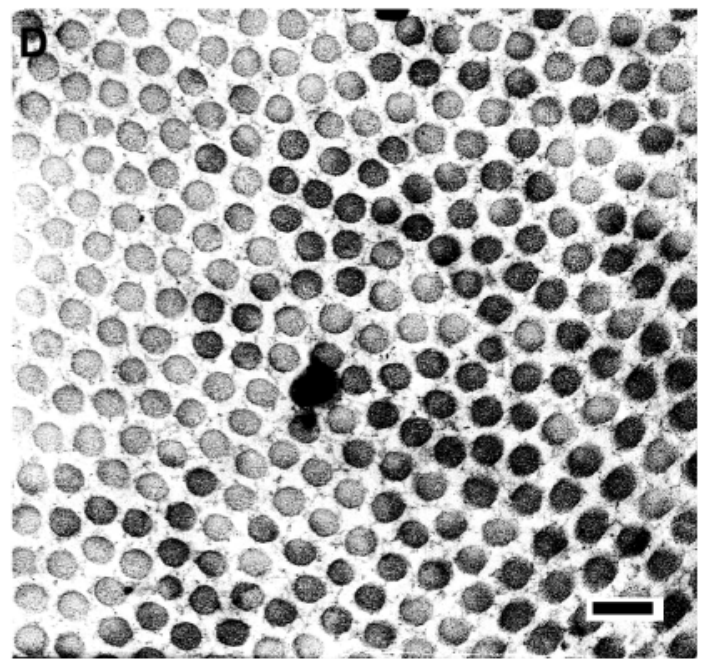

Neodrepanis hypoxantha light blue

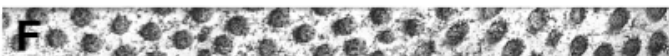

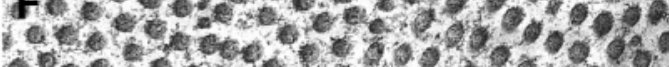

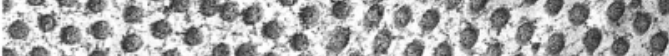

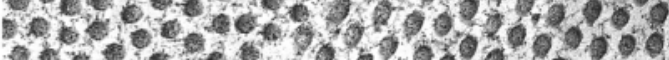

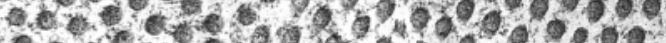

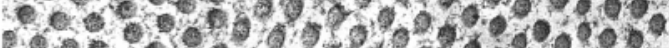

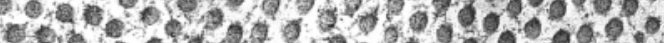

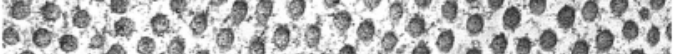

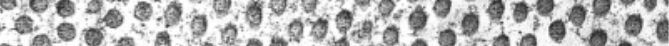
d.

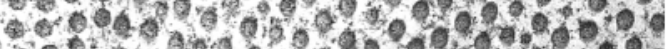
Réa

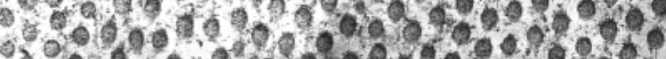

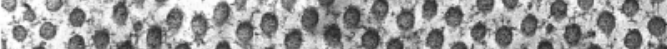

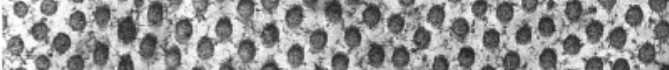
-

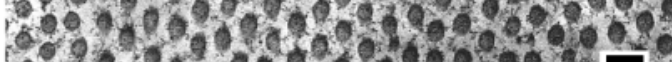

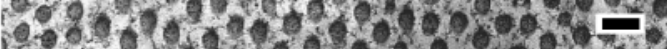

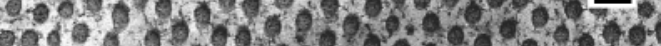



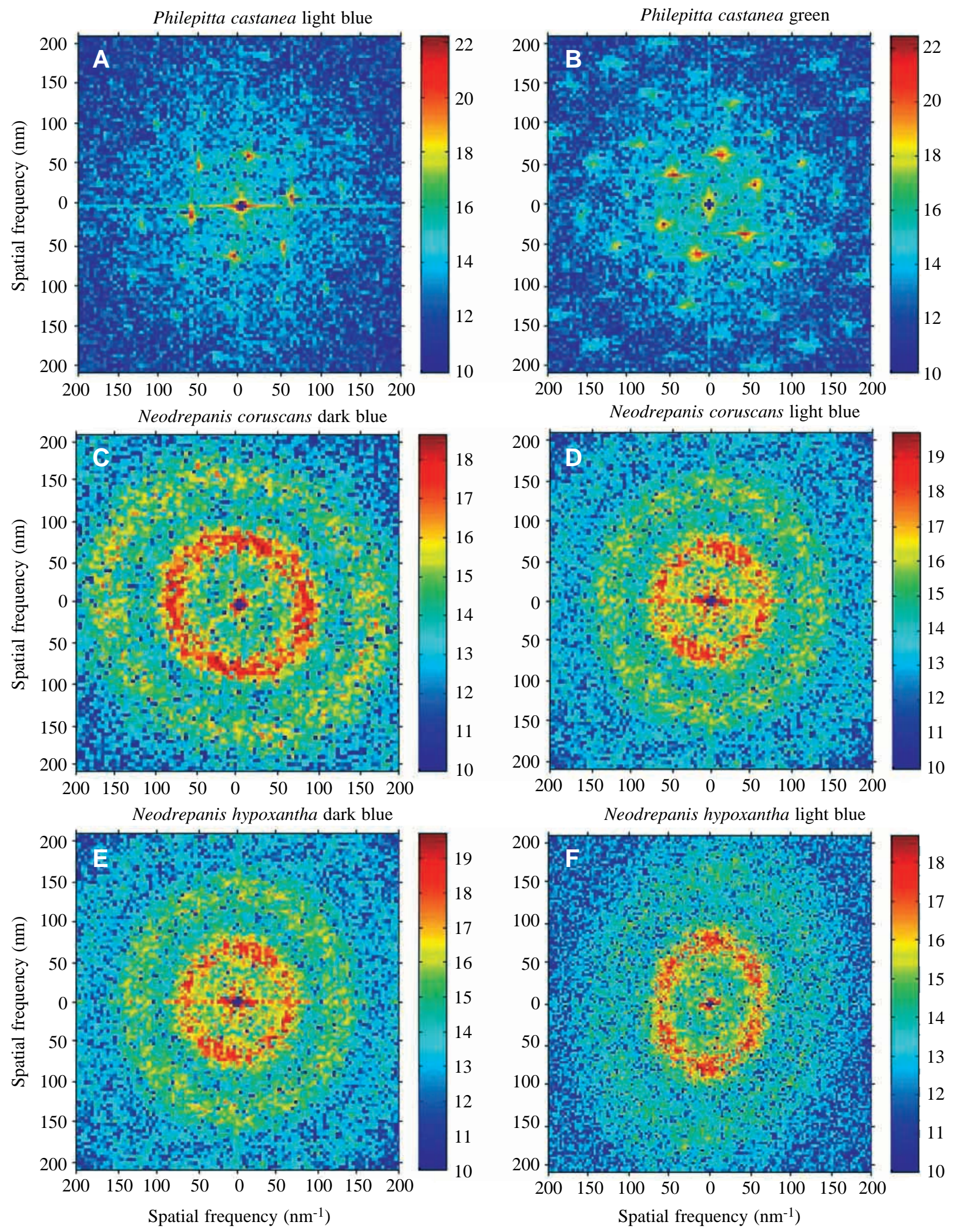

Fig. 6. Two-dimensional Fourier power spectra of transmission electron micrographs of colour-producing collagen arrays of asities. Philepitta castanea: (A) light blue, (B) green. Neodrepanis coruscans: (C) dark blue, (D) light blue. Neodrepanis hypoxantha: (E) dark blue, (F) light blue. The spatial frequency and direction of each value in the power spectrum are given by the length and direction, respectively, of a vector from the origin to that point. The magnitude of each value in the power spectrum is given by the colour (scale on right). Magnitudes are illustrated here as natural logarithms of the original values, but the original data are used in all calculations. 
Fig. 7. Normalized radial averages of single quadrants of the two-dimensional Fourier power spectra of colour-producing collagen arrays of asities. Philepitta castanea: (A) light blue, (B) green. Neodrepanis coruscans: (C) dark blue, (D) light blue. Neodrepanis hypoxantha: (E) dark blue, (F) light blue.

'leakage' among component spatial frequencies and the intervals used to create the radial average of the power spectrum (see below; Briggs and Henson, 1995).

\section{Discussion}

\section{Coherent scattering}

The vivid colours of the caruncles of three species of asities are produced by coherent scattering, or constructive interference, from arrays of parallel collagen fibres in the dermis. The observed reflectance spectra of all tissues show discrete peaks in the avian visible spectrum between 320 and $700 \mathrm{~nm}$ (Bennett and Cuthill, 1994). Given the behavioural evidence that asity caruncles function in intersexual communication (Prum and Razafindratsita, 1997), the substantial reflectance of dark blue Neodrepanis tissues in the near ultraviolet provides the first evidence of near-ultraviolet skin colours in bird skin and the first indication that ultraviolet skin colours may function in avian communication.

The discrete peaks of the observed reflectance spectra of all tissues do not conform to Rayleigh's inverse fourth power law (Fig. 4). These results effectively falsify a fundamental prediction of the incoherent Rayleigh scattering model: increasingly efficient scattering of smaller wavelengths.

As predicted by the coherent scattering model, the variation
Philepitta castanea light blue

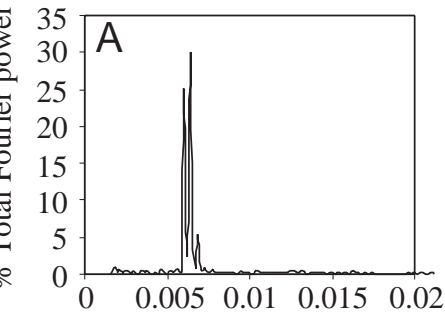

Neodrepanis coruscans dark blue

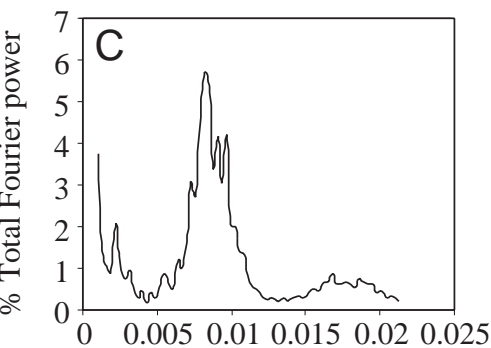

Neodrepanis hypoxantha dark blue

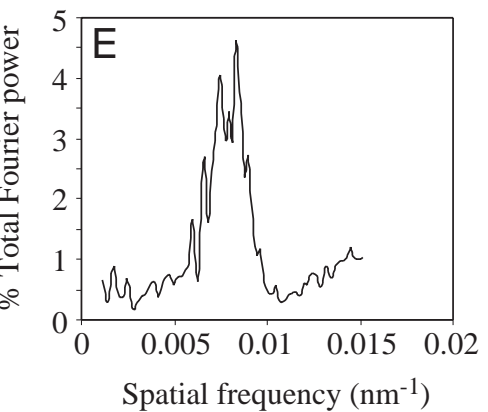

Neodrepanis hypoxantha light blue

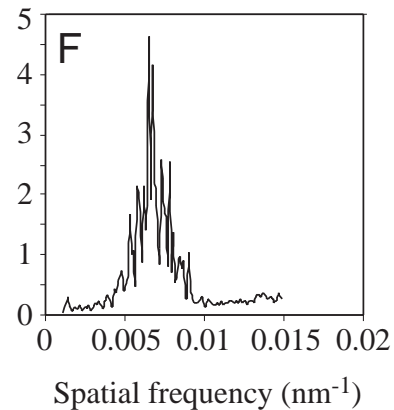

in hue among and within species is a physical consequence of variation in the nanostructure of the tissues. Both the Bragg and the discrete two-dimensional Fourier analyses demonstrate that larger distances between fibre centres coherently scatter longer wavelengths. Although both methods were subject to error (see below), both accurately predicted the relative hue of different tissues within a species and relatively accurately predicted the relative hue of all tissues. These analyses indicate that $\lambda_{\max }$ is not a simple function of fibre size. Collagen fibre diameter and interfibre distance can vary independently to contribute to the spatial periodicity of the tissue. For example, the dark blue Neodrepanis hypoxantha caruncle tissues $\left(\lambda_{\max }=403 \mathrm{~nm}\right)$ had larger-diameter fibres that were closer together than the light blue $N$. hypoxantha arrays $\left(\lambda_{\max }=465 \mathrm{~nm}\right)$, which had smaller-diameter fibres that were more widely spaced (Fig. 5E,F; Table 1).

\section{Hexagonal versus quasiordered nanostructure}

The collagen arrays of Neodrepanis and Philepitta castanea differ strikingly in nanostructure. In Neodrepanis, the collagen fibres are distributed in a quasiordered array with no planes of symmetry perpendicular to the fibres, whereas the fibres in $P$. castanea are regularly distributed in highly ordered hexagonal arrays. These differences in nanostructure were reproduced in the ring-like and hexagonal two-dimensional power spectra of 
these tissues. The ring-like power spectrum is indicative of equivalent nanostructure in all directions within the plane of the tissue and should theoretically yield a noniridescent colour (i.e. one that does not change with angle of observation; Prum et al., 1998, 1999). This prediction is congruent with the observed absence of iridescence in the Neodrepanis caruncles. But, the hexagonally patterned power spectrum of $P$. castanea conflicts with the similar absence of iridescence in that species. However, the light-scattering tissues in both species are composed of many layers of collagen macrofibrils that are not regularly oriented to the surface of the tissue (Fig. 3). Because of the absence of structural periodicity at larger spatial scales, light incident on the $P$. castanea caruncle will intersect with a larger number of collagen arrays with many different orientations as it passes through the tissue. The observed reflectance is the summation of coherently scattered reflections from all these arrays and will include wavelengths scattered from all angles of incidence. So, $P$. castanea tissues have the nanostructural potential to be iridescent, but lack the organization at larger spatial scales to produce iridescent colours.

The planar arrangement of the long narrow collagen fibres that constitute the arrays within these tissues should also result in substantial polarization of the scattered light waves. The long collagen fibres should scatter the component of incident light with a polarization parallel to the fibres more efficiently than incident light with other directions of polarization. As with iridescence, however, the lack of structural periodicity at larger spatial scales (Fig. 3) should prevent consistent polarization of the light scattered by the tissue as a whole. The highly polarized light waves scattered by the many differently ordered arrays within any section of the tissue should combine to yield a generally unpolarized reflection by the whole tissue.

\section{Evolution of colour and nanostructure}

The caruncles and collagen arrays of all asities are homologous structures that evolved in the common ancestor of the Philepitta and Neodrepanis (Raikow, 1987; Prum, 1993; Prum and Razafindratsita, 1997). The diversity of colours within and among asity species demonstrates that the nanostructure of the collagen fibre arrays has evolved and diversified since common ancestry. Field work on the polygynous breeding system and courtship display repertoire of $P$. castanea documents that these caruncles play a prominent role in intersexual communication and probably in mate choice by females (Prum and Razafindratsita, 1997). These secondary sexual caruncles probably evolved through intersexual selection and have probably diversified in colour and morphology by the same mechanism.

Female preferences for specific colours cannot select directly on collagen nanostructure. Rather, colour preferences can act only indirectly on nanostructure through the observable features of the reflectance spectrum. In an elegant application of the mathematical equivalence between a function and its transform (Briggs and Henson, 1995), the Fourier transform provides not only a method for understanding the relationship between the nanostructure and the physics of light scattering by a tissue, but also provides insight into the inverse problem of how female colour preferences produce changes in the nanostructure of tissues. In future research, we will address these questions specifically by analyzing the evolution of colour preferences and colour-producing nanostructured traits in an explicit phylogenetic context. However, some preliminary conclusions can be drawn from current data.

The quasiordered Neodrepanis arrays are closer in nanostructure to the plesiomorphic spatial organization of dermal collagen fibres than are the hexagonal arrays of $P$. castanea. Using outgroup comparison to polarize this variation, the hexagonal fibre arrangement is derived, and it evolved from the plesiomorphic quasiordered state in either $P$. castanea or the ancestor of the genus Philepitta, depending on the unknown nanostructure of the caruncle tissue of Philepitta schlegeli.

A hexagonal array is the simplest possible arrangement for a tissue in which neighbouring fibres are all the same distance apart. Interestingly, several sections of tissues from one specimen of Neodrepanis hypoxantha showed collagen arrays that approach the hexagonal arrangement of $P$. castanea over a local area (Fig. 8). The Fourier power spectra of these sections show a 'wedding ring' pattern of a thin ring with six high-intensity peaks arranged in a nearly hexagonal pattern within the ring (Fig. 8). The power spectrum of this unusual section of tissue is intermediate between the ring and hexagonal patterns and indicates that the hexagonal fibre arrangement probably evolved by increasingly rigid specification of the distance between the fibres. As the ring in the Fourier power spectrum of a quasiordered tissue becomes thinner and thinner (Fig. 8), the fibres ultimately converge on a hexagonal nanostructure.

Functionally, a tissue with a narrower ring in its power spectrum will produce a more saturated colour. Accordingly, hexagonal arrays could have evolved from quasiordered arrays through selection for more-saturated purer colours. The power spectra and radial averages of both colours of $P$. castanea tissue showed exceptionally narrow peaks (Figs 6A,B, 7A,B; Table 1) that would predict a highly saturated reflectance (Fig. 4A,B). Although the hexagonal arrays of Philepitta castanea produced the most-saturated colours of any tissues examined, they were not significantly more saturated than some hues produced by quasiordered arrays in Neodrepanis (Fig. 4; Table 1). It is possible that $P$. castanea caruncles do produce purer hues than Neodrepanis arrays in life, and that these broader reflectance peaks are a consequence of changes in nanostructure between collection and the reflectance measurements. If the current reflectance spectra are accurate, however, then the less-than-predicted saturation of hue in $P$. castanea may be due to variation in array size among the many arrays within the tissue. Each macrofibre may have a highly hexagonal distribution of fibres with a narrow band of spatial frequency variation but, if there is variation in spatial frequency among macrofibrils, then the overall hue produced may be no more saturated than that produced by a less organized array. Both these alternative hypotheses will be tested in future research. 

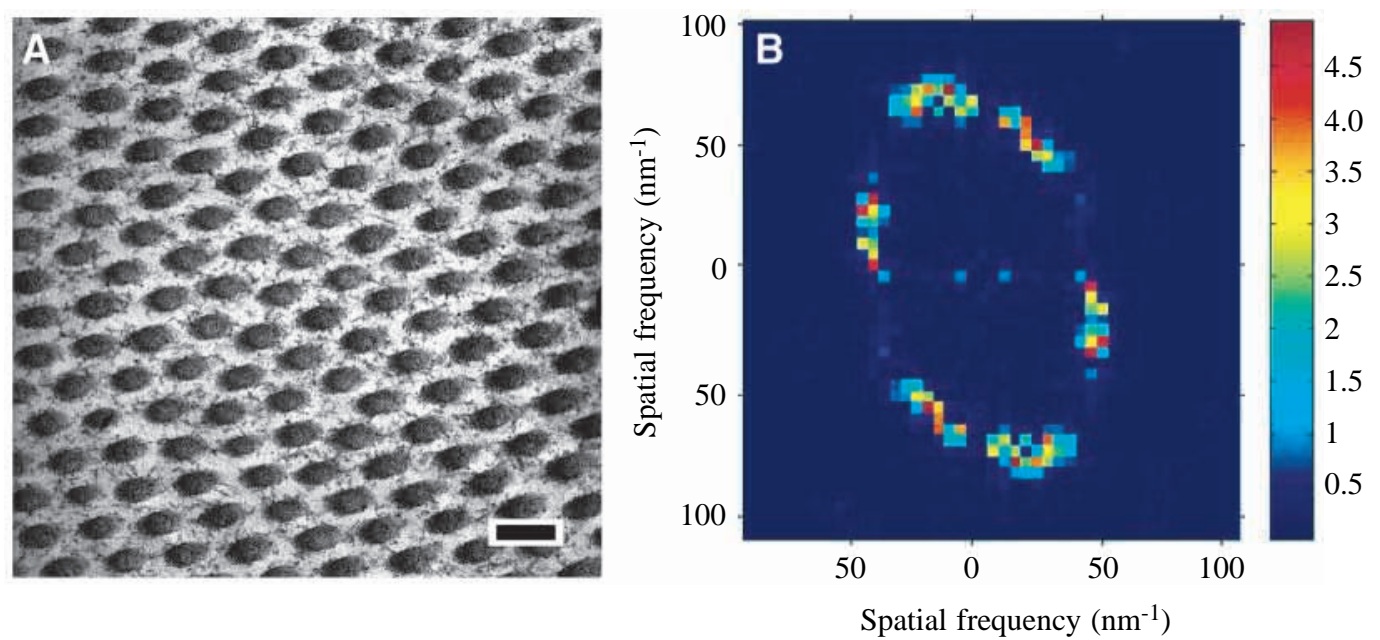

Fig. 8. Nanostructure of a nearly hexagonal array of collagen fibres in light blue caruncle tissue of Neodrepanis hypoxantha. (A) Transmission electron micrograph. Scale bar, $200 \mathrm{~nm}$. (B) Two-dimensional Fourier power spectrum. This specimen is intermediate in nanostructure between the typically quasiordered Neodrepanis and the hexagonally ordered Philepitta castanea. The power spectrum reveals an intermediate 'wedding ring' pattern with six hexagonally arranged peaks within a thin ring. The magnitude of each value in the power spectrum is given by the colour (scale on right). Magnitudes are illustrated here as natural logarithms of the original values, but the original data are used in all calculations.

\section{Evolution of anatomy}

The asities exhibit additional variation in the anatomy of the structurally coloured caruncles. In Neodrepanis, the collagenous arrays form a thick outer layer of the dermis that is underlain by a layer of melanocytes (Fig. 3D-G). The collagen fibres themselves form a 'wavy' interconnected network of colour-producing arrays (Fig. 3E,G). In Philepitta castanea, the derived, cone-shaped papillae enclose a capsule of distinctly separate collagen macrofibrils (Fig. 3A-C). In addition, the caruncles of $P$. castanea are restricted to the area above the eye and are extensible (Prum and Razafindratsita, 1997). These derived anatomical features in $P$. castanea appear to function directly in the presentation of the colour-producing collagen to ambient light and to potential observers. The caruncle papillae raise the arrays above the level of the surrounding tissue, increase the surface area and directions over which light can penetrate the collagen arrays and promote more efficient colour production by the dermis. Selection for the colour and appearance of the caruncles has led to substantial diversification in the anatomy of the colourproducing caruncles since the origin of the asity clade.

The papillae of the supraorbital caruncles of Philepitta castanea appear to be unique among vertebrates. Although these papillae show some similarities with feather and scale primordia, they do not appear to be homologous with either of these structures. Rather, it appears that the dermal papillae of $P$. castanea constitute a novel origin of an integumental appendage within vertebrates, along with scale, feather and hair (M. Harris, personal communication). Ultimately, it would be fascinating to study the development of these structures from this perspective. One could test general hypotheses about the development of vertebrate integumental appendages with a novel, evolutionarily independent structure with many interesting features. For example, the papillae of $P$. castanea develop and atrophy once annually. They are closely packed on the surface of the skin in a pattern more similar to scales. However, unlike other vertebrate integumental appendages, the papillae of $P$. castanea appear to lack any posterior-anterior orientation.

\section{Bragg versus Fourier analysis}

We present two alternative methods of analyzing the relationship between the nanostructure of scatterers and the light-scattering behaviour of the tissues. The Bragg model assumes an idealized crystal structure and employs measurements from the tissues to predict a peak hue only. The two-dimensional Fourier method makes no assumptions about the structure of the tissues and produces a description of the spatial periodicity in refractive index in the tissue and a predicted reflectance spectrum. The Fourier method presents a substantial advance since it objectively and quantitatively describes the nanostructure that the Bragg method assumes. The two-dimensional Fourier power spectrum of a tissue demonstrates directly whether it will scatter visible light coherently. The Fourier method also describes the lightscattering behaviour of the tissue from the entirety of the available relevant information: the spatial variation in refractive index. It eliminates the errors and biases associated with trying to describe a complex tissue in a few average or idealized measurements. Furthermore, the Fourier method can provide a more detailed description of the light-scattering behaviour of a tissue in the form of a predicted reflectance spectra. These advantages are particularly crucial in analyzing colour production by quasiordered tissues that explicitly violate the spatial assumptions of the Bragg model. In summary, the results of this study and previous applications of this Fourier method to quasiordered biological arrays (Prum et al., 1998, 1999) demonstrate the efficacy of this method to the biophysical analysis of structural coloration. We are currently working on 
demonstrating theoretically that the Fourier method used here also converges on the same solutions as those produced by Bragg analysis and thin-film optical methods for colour production by laminar and crystal-like arrays. Thus, the Fourier method will provide a single computationally tractable tool that is appropriate for biophysical analysis of any coherently scattering biological structure.

Both the Bragg and Fourier analyses are subject to numerous sources of error that affect the accuracy of their reflectance predictions. Analysis of these sources of error may indicate how the methods can be improve in future investigations. Both methods produced generalized underestimates of $\lambda_{\max }$ for all tissues (Bragg error, 18-132 nm, mean $69 \mathrm{~nm}$ or $11 \%$; Fourier error, $24-117 \mathrm{~nm}$, mean $77 \mathrm{~nm}$ or $16 \%$ ). As one would expect, the Bragg model was more accurate in predicting $\lambda_{\max }$ of $P$. castanea tissues (Table 1), which are more crystal-like in nanostructure and conform better to the assumptions of the model.

There are two plausible explanations of the generalized underestimates of the peak hues of all tissues. First, the techniques employed in the preparation of the material for electron microscopy may have shrunk the tissues. Tissue shrinkage is difficult to quantify experimentally but could be between 5 and $30 \%$ depending on the tissues and conditions (B. Cutler, personal communication). The preparation analyzed here may have been particularly variable because the tissues were collected in the field at different times under variable conditions and were prepared for electron microscopy at different times as well. Subtle undocumented variations in the solutions or conditions could have introduced additional variation to the samples. However, the glutaraldehyde preservation used here was a substantial improvement over the formalin-fixed material of $P$. castanea examined by Prum et al. (1994), which had changed colour substantially before transmission electron microscope analysis.

Second, the underestimates of the peak hue of reflectance may have arisen from underestimates of the average refractive index of the tissues. The refractive index of collagen has been accurately estimated from a number of sources, but the refractive index of the mucopolysaccharide matrix between the fibres in the avian dermis is unknown. We used a value of 1.35 that was measured for the mucopolysaccharide matrix between the collagen fibres of human cornea (Maurice, 1984). Although the matrix in the avian dermis is likely to be chemically similar, we do not know whether this is an accurate estimate of the refractive index of the mucopolysaccharide in the tissues. The method used in the Fourier analyses to produce a weighted average of the refractive index of the tissues is likely to be quite accurate. In addition, it is possible that the techniques of tissue fixation used affected the refractive indices of the collagen or mucopolysaccharide matrix.

An additional error in the Fourier-predicted reflectance spectra came from the production of the radial average power of the power spectrum from a square matrix. The shape and the position of the resulting Fourier-predicted reflectance spectra can vary with the size of the radial interval. Too small an interval results in some empty intervals without any values, whereas too large an interval produces substantially fewer intervals. Both errors can create 'leakage' in which the energy of a specific spatial frequency is distributed among other spatial frequencies within the transform. Leakage is a generalized error in discrete Fourier analysis that is caused by transforming the data into the sum of a discrete number of Fourier frequencies that are determined by the sample size $N$ $(N / 2, N / 3, N / 4, \ldots N / N)$ (Briggs and Henson, 1995). Leakage can best be addressed by digitizing images at higher resolution and increasing the data set sizes. Although this will make the calculations substantially more intensive, it could raise the resolution of the radial average power spectra over those spatial frequencies that produce visible colours.

Given that tissue shrinkage is the only source of error that is known to be systematically skewed towards underestimation, the generalized underestimates of the peak hues of all tissues indicate that tissue shrinkage may be the most important overall source of error.

We thank the National Association for the Management of Protected Areas of Madagascar (ANGAP) for permission to conduct the field research and to collect the specimens that made these investigations possible. The Division of Ornithology of the Field Museum of Natural History kindly loaned the specimens for the research. The light microscope histology was performed by Rosetta S. Barkely, University of Kansas Medical School, and specimen preparation for electron microscopy was performed by Bruce Cutler, University of Kansas EM Laboratory. Computer facilities were made available by the Department of Mathematics, University of Kansas. The manuscript was improved by the comments of two anonymous reviewers. The photograph in Fig. 1C was taken by Steve Zack. This research was supported by grants from the National Science Foundation to R.O.P. (DEB-9318273) and R.H.T. (DMS-9696267) and by grants from the University of Kansas Graduate Research Funds and the National Geographic Society to R.O.P.

\section{References}

Amadon, D. (1979). Philepittidae. In Check-list of Birds of the World (ed. M. A. Traylor), pp. 229-308. Cambridge, MA: Museum of Comparative Zoology, Harvard University.

Auber, L. (1957). The distribution of structural colors and unusual pigments in the Class Aves. Ibis 99, 463-476.

Bagnara, J. T. and Hadley, M. E. (1973). Chromatophores and Color Change. New Jersey: Prentice Hall.

Benedek, G. B. (1971). Theory of transparency of the eye. Appl. Optics 10, 459-473.

Bennett, A. T. D. and Cuthill, I. C. (1994). Ultraviolet vision in birds: what is its function? Vision Res. 34, 1471-1478.

Bohren, C. F. and Huffman, D. R. (1983). Absorption and Scattering of Light by Small Particles. New York: John Wiley \& Sons.

Bragg, W. H. and Bragg, W. L. (1915). X-rays and Crystal Structure. London: G. Bell. 
Briggs, W. L. and Henson, V. E. (1995). The DFT. Philadelphia, PA: Society for Industrial and Applied Mathematics.

Durrer, H. (1962). Schillerfarben beim Pfau (Pavo cristatus L.). Verh. Naturf. Ges. Basel 73, 204-224.

Durrer, H. and Villiger, W. (1966). Schillerfarben der Trogoniden. J. Orn. 107, 1-26.

Durrer, H. and Villiger, W. (1970). Shilleradien des Goldkuckucks. Z. Zellforsch. 109, 407-413.

Dyck, J. (1971). Structure and spectral reflectance of green and blue feathers of the Lovebird (Agapornis roseicollis). Biol. Skrifter 18, $1-67$.

Dyck, J. (1976). Structural colours. Proc. Int. Orn. Congr. 16, 426-437.

Fox, D. L. (1976). Animal Biochromes and Structural Colors. Berkeley,CA: University of California Press.

Gisselberg, M., Clark, J. I., Vaezy, S. and Osgood, T. (1991). A quantitative evaluation of Fourier components in transparent and opaque calf cornea. Am. J. Anat. 191, 408-418.

Hawkins, F. (1994). The nest of Schlegel's Asity Philepitta schlegeli. Bull. Afr. Bird Club 1, 77-78.

Lambert, F. and Woodcock, M. (1996). Pittas, Broadbills and Asities. Sussex: Pica Press.

Lucas, A. M. and Stettenheim, P. R. (1972). Avian Anatomy Integument. Washington, DC: US Department of Agriculture Handbook.

MATLAB Research Guide (1992). MATLAB. Natick, MA: The Mathworks, Inc.

Maurice, D. M. (1984). The cornea and sclera. In The Eye (ed. H. Davson), pp. 1-158. New York: Academic Press.

Parker, A. R. (1999). Invertebrate structural colours. In Functional Morphology of the Invertebrate Skeleton (ed. E. Savazzi). London: John Wiley \& Sons.

Prum, R. O. (1993). Phylogeny, biogeography and evolution of the broadbills (Eurylaimidae) and asities (Philepittidae) based on morphology. Auk 110, 304-324.

Prum, R. O. (1999). The anatomy and physics of avian structural coloration. In Proceedings of the 22nd International Ornithological Congress (ed. N. J. Adams and R. H. Slotow). Johannesburg: BirdLife South Africa.

Prum, R. O., Morrison, R. L. and Ten Eyck, G. R. (1994).
Structural color production by constructive reflection from ordered collagen arrays in a bird (Philepitta castanea: Eurylaimidae). $J$. Morph. 222, 61-72.

Prum, R. O. and Razafindratsita, V. R. (1997). Lek behaviour and natural history of the Velvet Asity Philepitta castanea (Eurylaimidae). Wilson Bull. 109, 371-392.

Prum, R. O., Torres, R. H., Williamson, S. and Dyck, J. (1998). Coherent light scattering by blue feather barbs. Nature 396, 28-29.

Prum, R. O., Torres, R. H., Williamson, S. and Dyck, J. (1999). Two-dimensional Fourier analysis of the spongy medullary keratin of structurally coloured feather barbs. Proc. R. Soc. Lond. B 266, 13-22.

Raikow, R. J. (1987). Hindlimb myology and evolution of the Old World suboscine passerine birds. Orn. Monogr. 41, 1-81.

Rawles, M. E. (1960). The integumentary system. In Biology and Comparative Physiology of Birds (ed. A. J. Marshall), pp. 189-240. New York: Academic Press.

Senechal, M. (1996). Quasicrystals and Geometry. Cambridge: Cambridge University Press.

Thompson, C. M. and Shure, L. (1995). MATLAB Image Processing Toolbox User's Guide. Natick, MA: The MathWorks, Inc.

Vaezy, S. and Clark, J. I. (1991). A quantitative analysis of transparency in the human sclera and cornea using Fourier methods. J. Microsc. 163, 85-94.

Vaezy, S. and Clark, J. I. (1993). Quantitative analysis of the microstructure of the human cornea and sclera using 2-D Fourier methods. J. Microsc. 175, 93-99.

Vaezy, S. and Clark, J. I. (1995). Characterization of the cellular microstructure of ocular lens using two-dimensional power law analysis. Ann. Biomed. Eng. 23, 482-490.

Vaezy, S., Clark, J. I. and Clark, J. M. (1995a). Quantitative analysis of lens cell microstructure in selenite cataract using a twodimensional Fourier analysis. Exp. Eye Res. 60, 245-255.

Vaezy, S., Smith, L. T., Milaninia, A. and Clark, J. I. (1995b). Two-dimensional Fourier analysis of electron micrographs of human skin for quantification of the collagen fiber organization in the dermis. J. Electron Microsc. 44, 358-364.

van de Hulst, H. C. (1981). Light Scattering by Small Particles. New York: Dover.

Young, A. T. (1982). Rayleigh scattering. Phys. Today 35, 42-48. 